\title{
AP-1 Complex
}

National Cancer Institute

\section{Source}

National Cancer Institute. AP-1 Complex. NCI Thesaurus. Code C17450.

A dimeric complex of related bZIP JUN, FOS, MAF and ATF transcription factors that must dimerize in order to bind to AP1 recognition sites (TPA-Responsive Element, TRE) or CAMP response elements in DNA, AP-1 controls basal and inducible transcription of several genes. 